\title{
Cardiovascular Disease Risk Profile in Japanese Midlife Migraineurs
}

\author{
Ken Ikedaa, c, Yuji Kawase ${ }^{\mathrm{a}}$, Takanori Takazawa ${ }^{\mathrm{a}}$, Osamu Kano, \\ Masaki Tamura $^{\text {b }}$ Yasuo Iwasaki ${ }^{a}$
}

\begin{abstract}
Background: Migraine is a common disabling disorder. A significant association between migraine and cardiovascular disease (CVD) has been reported in European and North American population. Little is known about CVD risk factors in Asian migraineurs. We aimed to clarify CVD risk profile of midlife migraineurs in Japan.

Methods: A total of 596 subjects (409 women and 187 men) were diagnosed as migraine with aura (MA) and without aura (MO), according to the ICHD-II criteria. CVD risk factors were analyzed on body mass index, west circumference/height, smoking index, blood pressure (BP), serum lipid levels, fasting blood sugar, hemoglobin $\mathrm{A}_{1 \mathrm{C}}$, C-reactive protein, and a family history of CVD or stroke. Those factors were compared between migraineurs and 599 healthy controls matched by age and sex.
\end{abstract}

Results: Mean age (SD) of migraineurs was $44.6(9.4)$ years, 44.3 (9.4) in women and 45.2 (9.3) in men. Mean duration of migraine (SD) was 16.7 (11.4) years, 18.7 (12.2) in women and 13.3 (9.1) in men. Frequency and score of migraine attacks were higher significantly in women compared to men $(\mathrm{P}<0.01)$. As compared to con-

Manuscript accepted for publication January 27, 2012

\footnotetext{
${ }^{a}$ Department of Neurology, Toho University Omori Medical Center, Tokyo, Japan

${ }^{b}$ Department of Preventive Medicine, PL Tokyo Health Care Center, Tokyo, Japan

${ }^{\mathrm{c} C}$ Corresponding author: Ken Ikeda, Department of Neurology, Toho University Omori Medical Center, 6-11-1, Omorinishi, Otaku, Tokyo, 143-8541, Japan.Email: keni@med.toho-u.ac.jp
}

doi:10.4021/jnr82w trols, systolic and diastolic BP was significantly increased in female and male migraineurs $(\mathrm{P}<0.01)$. High-density lipoprotein cholesterol was decreased $(\mathrm{P}<0.01)$, and total cholesterol (TC) and lowdensity lipoprotein cholesterol (LDL-C) were increased in sera of female and male migraineurs $(\mathrm{P}<0.01)$. Serum triglyceride levels were higher in male migraineurs $(\mathrm{P}<0.01)$. Migraineurs had higher frequency of relatives with CVD or stroke $(\mathrm{P}<0.01)$. With respect to migraine subtypes, MA and MO sufferers significantly elevated $\mathrm{BP}(\mathrm{P}<0.05)$ and serum levels of TC and LDL-C $(\mathrm{P}<0.01)$.

Conclusions: The present study indicated unfavorable CVD risk factors of BP, serum lipid levels and a family history of CVD or stroke in middle-aged migraineurs. The similarity of CVD risk profile was first confirmed between Japanese and Western migraineurs.

Keywords: Migraine; Cardiovascular disease risk profile; Blood pressure; Lipid; Family history of cardiovascular disease or stroke

\section{Introduction}

Migraine is a primary, chronic-intermittent headache disorder that affects a large proportion of the population, predominantly middle-aged women $[1,2]$. Migraine is associated with stroke and cardiovascular disease (CVD) [3-19]. Potential mechanisms of increased risk for ischemic stroke and CVD have been postulated in migraineurs [5, 9, 14-16]. Distinct backgrounds of CVD risk profile were highlighted in European and North American migraineurs [10, 13, 1720]. However, little is known about CVD risk factors in large number of Asian migraineurs. Here, we aimed to evaluate CVD risk profile of midlife migraineurs in Japan.

\section{Materials and Methods}

\section{Clinical assessment of migraine}

Migraine was diagnosed according to the criteria of the International Classification of Headache Disorders; 2nd Edition [21]. Migraine was classified into migraine with aura (MA) and migraine without aura (MO). Severity of migraine 
Table 1. Clinical Background of Migraineurs

\begin{tabular}{|c|c|c|c|}
\hline & $\begin{array}{l}\text { Total }(n=596) \\
\qquad(n=596)\end{array}$ & Women $(n=409)$ & $\operatorname{Men}(n=187)$ \\
\hline Mean age (SD) years & $44.6(9.4)$ & $44.3(9.4)$ & $45.2(9.3)$ \\
\hline Mean duration of migraine (SD) years & $16.7(11.4)$ & $18.7(12.2)$ & $13.3(9.1)$ \\
\hline \multicolumn{4}{|l|}{ Migraine subtypes } \\
\hline MA sufferers & $90(15.1 \%)$ & $68(16.6 \%)$ & $22(11.8 \%)$ \\
\hline MO sufferers & $506(84.9 \%)$ & $341(83.4 \%)$ & $165(88.2 \%)$ \\
\hline \multicolumn{4}{|l|}{ Frequency of migraine attacks } \\
\hline$\geq 1 \mathrm{attack} / \mathrm{month}$ & $354(59.4 \%)$ & $271(66.3 \%)^{*}$ & $86(45.9 \%)$ \\
\hline$<1$ attack/month & $242(50.6 \%)$ & $138(33.7 \%)$ & $101(54.1 \%)$ \\
\hline Mean scores (SD) of HIT-6 & $61.4(8.7)$ & $63.1(8.9)^{*}$ & $57.7(8.5)$ \\
\hline Family history of migraine & $329(55.2 \%)$ & $235(57.5 \%)$ & $94(50.3 \%)$ \\
\hline
\end{tabular}

MA: migraine with aura; MO: migraine without aura; HIT-6: headache impact test- 6 . ${ }^{*} \mathrm{P}<0.01$ between women and men.

was scaled using functional disability score of Headache Impact Test-6 (HIT-6) [22]. Migraineurs who had more than one attack in the previous year were selected. Migraine sufferers who never had migraine attacks in the previous year were excluded from the present study. Frequencies of migraine attacks were denoted as $<1$ attack per month or $\geq 1$ attack per month.

\section{Study participants}

A total of 596 subjects (409 women and 187 men) were diagnosed consecutively as migraine between 2006 and 2009 in two Japanese medical centers: Toho University Omori Medical Center and PL Tokyo Health Care Center. For comparison of CVD risk factors, 599 age- and sex- control subjects without prior history of migraine were prepared. To evaluate spontaneous CVD risk profile, migraineurs and controls who used hormonal contraceptive, antihypertensive, diabetic and dyslipidemic drugs were excluded from this study. The present study was approved by Ethics Committee of Toho University Omori Medical Center and PL Tokyo Health Care Center. The informed consent for this study was obtained from all participants.

\section{CVD risk factors}

CVD risk factors were analyzed on the following 9 items: body mass index (BMI), west circumference/height, smoking index (cigarettes/day X years), blood pressure (BP), serum levels of lipids, fasting blood sugar (FBS), serum levels of hemoglobin $\mathrm{A}_{1 \mathrm{C}}\left(\mathrm{HbA}_{1 \mathrm{c}}\right)$, serum levels of high sensitivity C-reactive protein (CRP), and a family history of CVD or stroke. Serological measurement of lipids contained total cholesterol (TC), high-density lipoprotein cholesterol (HDLC), low-density lipoprotein cholesterol (LDL-C) and triglyceride (TG). Fasting blood samples were obtained from the antecubital vein in controls and migraineurs during a headache-free period.

\section{Statistical analysis}

Statistical analyses of migraine frequency and a family history of CVD or stroke used $\chi^{2}$-test. Other CVD risk factors and HIT-6 scores were analyzed by unpaired Student's t-test and one-way analysis of variance. All statistical significances were set at $\mathrm{P}<0.05$.

\section{Results}

\section{Clinical background of migraineurs}

Mean age (SD) of migraineurs was 44.6 (9.4) years, 44.3 (9.4) years in women and $45.2(9.3)$ years in men. Mean duration of migraine (SD) was 16.7 (11.4) years, 18.7 (12.2) years in women and 13.3 (9.1) years in men. Frequency of $\geq 1 \mathrm{attack} / \mathrm{month}$ was increased in women more than men $(\mathrm{P}$ $<0.01)$. Female migraineurs had significant higher HIT-6 scores as compared to male migraineurs $(\mathrm{P}<0.01)$. Those results suggested that frequency and severity of migraine at- 
Table 2. CVD Risk Factors of Migraineurs and Controls

\begin{tabular}{|c|c|c|c|c|}
\hline & \multicolumn{2}{|c|}{ Migraineurs $(n=596)$} & \multicolumn{2}{|c|}{ Controls $(n=599)$} \\
\hline & Women $(n=409)$ & $\operatorname{Men}(n=187)$ & Women $(n=402)$ & Men $(n=197)$ \\
\hline Mean age (SD) years & $44.3(9.4)$ & $45.3(9.4)$ & $44.2(9.3)$ & $45.7(8.1)$ \\
\hline BMI kg/m² & $21.5(3.2)$ & $24.0(3.7)$ & $21.2(2.6)$ & $23.7(3.1)$ \\
\hline West/height & $48.9(5.5)$ & $49.2(5.5))$ & $49.2(5.5)$ & $48.9(4.7)$ \\
\hline Smoking index & $56.2(118.7)$ & $287.2(334.0)$ & $59.3(140.6)$ & $282.2(277.0)$ \\
\hline SBP mmHg & $109.4(14.5)^{*}$ & $119.7(13.9)^{\dagger}$ & $106.8(13.6)$ & $116.2(13.3)$ \\
\hline DBP mm Hg & $68.6(9.5)^{*}$ & $73.7(9.5)^{\dagger}$ & $66.0(8.8)$ & $70.7(9.5)$ \\
\hline $\mathrm{FBS} \mathrm{mg} / \mathrm{dL}$ & $93.5(8.8)$ & $99.9(15.4)$ & $92.6(11.7)$ & $99.6(12.5)$ \\
\hline $\mathrm{HbA}_{1 \mathrm{c}} \%$ & $5.3(0.9)$ & $5.3(0,9)$ & $5.3(1.0)$ & $5.4(1.0)$ \\
\hline $\mathrm{TC} \mathrm{mg} / \mathrm{dL}$ & $210.3(34.2)^{*}$ & $209.3(32.4)^{\dagger}$ & $201.5(35.2)$ & $202.0(33.0)$ \\
\hline HDL-C mg/dL & $67.4(14.2)^{* *}$ & $53.5(13.3)^{\dagger}$ & $71.8(14.8)$ & $56.5(13.6)$ \\
\hline LDL-C mg/dL & $118.9(30.1)^{*}$ & $129.8(29.0)^{\dagger}$ & $109.6(30.6)$ & $121.5(30.5)$ \\
\hline $\mathrm{TG} \mathrm{mg} / \mathrm{dL}$ & $71.7(40.7)$ & $134.5(91.6)^{\dagger}$ & $67.3(33.4)$ & $112.0(77.8)$ \\
\hline $\mathrm{CRP} \mathrm{mg} / \mathrm{dL}$ & $0.09(0.24)$ & $0.13(0.21)$ & $0.09(0.32)$ & $0.23(0.53)$ \\
\hline FH of CVD or stroke & $89(21.8 \%)^{* *}$ & $38(20.3 \%)^{\dagger}$ & $51(12.7 \%)$ & $21(10.7 \%)$ \\
\hline
\end{tabular}

${ }^{*} P<0.01$ and ${ }^{* *} P<0.001$ between female migraineurs and female controls. $\dagger P<0.01$ between male migraineurs and male controls. CVD: cardiovascular disease; BMI: body mass index; SBP: systolic blood pressure; DBP: diastolic blood pressure; FBS: fasting blood sugar; $\mathrm{HbA}_{1 c}$ : hemoglobin $\mathrm{A}_{1 c}$; TC: total cholesterol; HDL-C: high-density lipoprotein cholesterol; LDL-C: low-density lipoprotein cholesterol; TG: triglyceride; CRP: C-reactive protein; FH: family history.

tacks were impaired in women more than men (Table 1).

\section{CVD risk profile of migraineurs and controls}

CVD risk factors of women and men were listed in Table 2. As compared to controls, systolic and diastolic BP was significantly increased in male and female migraineurs $(\mathrm{P}<$ $0.01)$. Serum levels of lipids differed statistically between migraineurs and controls. TC and LDL-C were increased in sera of female $(\mathrm{P}<0.01)$ and male migraineurs $(\mathrm{P}<$ 0.01). Serum levels of HDL-C were decreased in female migraineurs $(\mathrm{P}<0.001)$ and male migraineurs $(\mathrm{P}<0.01)$. Serum levels of TG were increased in male migraineurs $(\mathrm{P}<$ 0.01). As compared to controls, frequency of relatives with CVD or stroke was increased approximate 2-fold in female $(\mathrm{P}<0.001)$ and male migraineurs $(\mathrm{P}<0.01)$. There were no significant differences of BMI, west circumference/height, smoking index, FBS, $\mathrm{HbA}_{1 \mathrm{c}}$ and $\mathrm{CRP}$ between migraineurs and controls. Migraine subtypes and CVD risk profiles were expressed in Table 3. A significant elevation of systolic and diastolic BP existed in MA and MO sufferers, in comparison with controls $(\mathrm{P}<0.05)$. Serum levels of TC and LDL-C differed significantly among MA, MO and control subjects $(\mathrm{P}<$ 0.01). A family history of CVD or stroke was more frequent in MA and MO sufferers than controls $(\mathrm{P}<0.01)$. There were no significant differences of CVD risk factors between MA and MO sufferers.

\section{Discussion}

We first reported the CVD risk profile in large number of Japanese midlife migraineurs. Our migraineurs had higher $\mathrm{BP}$, higher serum levels of TC and LDL-C, lower serum levels of HDL-C and higher rates of CVD or stroke relatives in women and men. These unfavorable changes were found in both MA and MO sufferers.

Many previous studies supported the significant rela- 
Table 3. CVD Risk Factors of MA, MO and Control Subjects

\begin{tabular}{|c|c|c|c|}
\hline & MA $(n=90)$ & MO $(n=506)$ & Controls $(n=599)$ \\
\hline Mean age $(\mathrm{SD})$ years & $44.3(9.7)$ & $44.8(9.2)$ & $44.7(9.0)$ \\
\hline Women/men & $68 / 22$ & $341 / 165$ & $402 / 197$ \\
\hline $\mathrm{BMI} \mathrm{kg} / \mathrm{m}^{2}$ & $22.5(3.5)$ & $23.0(4.1)$ & $22.4(3.1)$ \\
\hline West/height & $48.9(5.6)$ & $49.7(5.6)$ & $48.6(4.7)$ \\
\hline Smoking index & $56.2(118.7)$ & $57.0(121.6)$ & $59.3(140.6)$ \\
\hline SBP mmHg & $115.4(15.5)^{*}$ & $114.7(14.9)^{\dagger}$ & $111.2(14.2)$ \\
\hline DBP mmHg & $70.2(9.1)^{*}$ & $70.3(9.7)^{\dagger}$ & $68.2(9.5)$ \\
\hline FBS mg/dL & $98.5(10.8)$ & $98.9(15.3)$ & $96.0(12.6)$ \\
\hline $\mathrm{HbA}_{1 \mathrm{c}} \%$ & $5.4(1.0)$ & $5.3(0.9)$ & $5.3(1.0)$ \\
\hline $\mathrm{TC} \mathrm{mg} / \mathrm{dL}$ & $210.5(35.1)^{* *}$ & $209.3(38.4)^{\dagger \dagger}$ & $201.5(34.2)$ \\
\hline HDL-C mg/dL & $62.9(14.2)$ & $63.2(15.6)$ & $64.4(16.2)$ \\
\hline LDL-C mg/dL & $125.9(34.1)^{* *}$ & $123.8(30.1)^{\dagger \dagger}$ & $115.4(31.1)$ \\
\hline $\mathrm{TG} \mathrm{mg} / \mathrm{dL}$ & 91.7 (70.7) & $88.5(81.6)$ & $88.8(63.2)$ \\
\hline CRP mg/dL & $0.11(0.30)$ & $0.10(0.41)$ & $0.11(0.33)$ \\
\hline FH of CVD or stroke & $25(27.8 \%)^{* *}$ & $102(20.2 \%)^{\dagger \dagger}$ & $72(12.0 \%)$ \\
\hline
\end{tabular}

${ }^{*} \mathrm{P}<0.05$ and ${ }^{* *} \mathrm{P}<0.01$ between female migraineurs and female controls. $\dagger \mathrm{P}<0.05$ and $\dagger \dagger \mathrm{P}<0.01$ between male migraineurs and male controls. CVD: cardiovascular disease; BMI: body mass index; SBP: systolic blood pressure; DBP: diastolic blood pressure;

FBS: fasting blood sugar; $\mathrm{HbA}_{1 \mathrm{c}}$ : hemoglobin $\mathrm{A}_{1 \mathrm{c}}$; TC: total cholesterol; HDL-C: high-density lipoprotein cholesterol; LDL-C: low-density lipoprotein cholesterol; TG: triglyceride; CRP: C-reactive protein; FH: family history.

tionship between migraine and vascular events, including CVD and ischemic stroke [3-19]. Several cohort studies revealed that MA was associated with CVD or ischemic stroke [10-12]. A recent Icelandic cohort study of midlife migraineurs also has shown that female MA is correlated with latelife cerebellar infarct-like lesions on magnetic resonance imaging [13]. Causative mechanism of those vascular disorders might contribute to prothrombotic actions, CVD risk factors, vascular reactivity, specific gene variants, congenital heart diseases, migraine attack frequency, migrainespecific treatment and pathophysiological involvements of the migraine [5, 9, 14-16]. Major prospective studies evaluated CVD risk factors in large number of migraineurs and non-migraineurs [10, 13, 17, 23]. The Genetic Epidemiology of Migraine study of Netherlands pointed out that MA sufferer increased the frequency of hypercholesterolemia, hypertension, and prior history of early onset CVD and stroke. Those risk factors did not differ statistically between MO sufferers and controls [17]. In the Women's Health Study of North America, women with MA and MO significantly increased BP and serum levels of TC and LDL-C, and decreased serum levels of HDL-C compared to controls [10]. Those hallmarks of BP and serum lipid levels were in the similar results to female migraineurs in the present study. In contrast, the Physicians' Health Study of North America suggested no significant linkages of CVD risk factors between male migraineurs and controls [23]. The AGES-Reykjavik long-term study of Iceland exhibited no significant elevation of BP and serum TC levels in midlife MA and MO sufferers. In addition, latelife migraineurs had no statistical changes of BP [13]. Other European studies mentioned the controversial result of CVD risk factors [18-20]. An Italian populationbased study (age $\geq 45$ years) showed that serum levels of $\mathrm{TC}$ and LDL-C were increased significantly in migraineurs $(\mathrm{n}=151)$ more than nonmigraineurs $(\mathrm{n}=1658)$ [18]. Hypercholesterolemia defined as TC $\geq 220 \mathrm{mg} / \mathrm{dL}$ was correlated independently with migraine in elderly men [18]. In an Austrian study, migraineurs and controls were divided into normal body weight and obesity. Serum levels of TC, LDL-C and oxidized LDL-C were increased significantly in normal 
weight migraineurs $(n=43)$ and obese migraineurs $(n=17)$ compared to normal weight controls $(n=61)$. There were no statistical differences of BP, and serum CRP and cytokines levels between migraineurs and controls with normal weight [19]. Those previous reports of serum lipid and CRP levels were mimicking to the present study. In contrast, previous Belgian study addressed that BP and serum levels of TC and LDL-C did not differ in young migraineurs $(\mathrm{n}=50)$ and controls $(n=50)$ without CVD risk factors. Only high sensitivity CRP was increased in interictal sera of migraineurs [20]. Thus, the present and previous studies advocated that unfavorable serum lipid profile was the most common CVD risk profile of migraineurs among many ethnics, including Europe, North American and Japan. In addition to interracial differences, variable backgrounds of migraineurs may reflect $B P$ values, serum levels of lipid and CRP.

In conclusion, the present study indicated elevation of $\mathrm{BP}$, unfavorable changes of serum lipid levels and high frequency of CVD or stroke relatives in middle-aged women and men with MA or MO. The similar CVD risk profile was first confirmed among Japanese, European and North American population. Further cohort studies are needed to elucidate prevalence of CVD or stroke in Japanese migraineurs.

\section{Conflicts of Interest}

All authors report no conflicts of interest.

\section{References}

1. Lipton RB, Bigal ME. The epidemiology of migraine. Am J Med. 2005;118 Suppl 1:3S-10S.

2. I 2. Ikeda K, Kashihara H, Hosozawa K, Anan K, Shimoma M, Tamura M, Iwasaki Y, et al. Brain check-upbased study of migraine in Japan. Headache Care. 2005; 2 (2): 75-80.

3. Henrich JB, Horwitz RI. A controlled study of ischemic stroke risk in migraine patients. J Clin Epidemiol. 1989;42(8):773-780.

4. Tzourio C, Iglesias S, Hubert JB, Visy JM, Alperovitch A, Tehindrazanarivelo A, Biousse V, et al. Migraine and risk of ischaemic stroke: a case-control study. BMJ. 1993;307(6899):289-292.

5. Donaghy M, Chang CL, Poulter N. Duration, frequency, recency, and type of migraine and the risk of ischaemic stroke in women of childbearing age. J Neurol Neurosurg Psychiatry. 2002;73(6):747-750.

6. Etminan M, Takkouche B, Isorna FC, Samii A. Risk of ischaemic stroke in people with migraine: systematic review and meta-analysis of observational studies. BMJ. 2005;330(7482):63.

7. Kurth T, Slomke MA, Kase CS, Cook NR, Lee IM, Ga- ziano JM, Diener HC, et al. Migraine, headache, and the risk of stroke in women: a prospective study. Neurology. 2005;64(6):1020-1026.

8. Stang PE, Carson AP, Rose KM, Mo J, Ephross SA, Shahar E, Szklo M. Headache, cerebrovascular symptoms, and stroke: the Atherosclerosis Risk in Communities Study. Neurology. 2005;64(9):1573-1577.

9. MacClellan LR, Giles W, Cole J, Wozniak M, Stern B, Mitchell BD, Kittner SJ. Probable migraine with visual aura and risk of ischemic stroke: the stroke prevention in young women study. Stroke. 2007;38(9):2438-2445.

10. Kurth T, Gaziano JM, Cook NR, Logroscino G, Diener HC, Buring JE. Migraine and risk of cardiovascular disease in women. JAMA. 2006;296(3):283-291.

11. Kurth T, Gaziano JM, Cook NR, Bubes V, Logroscino G, Diener HC, Buring JE. Migraine and risk of cardiovascular disease in men. Arch Intern Med. 2007;167(8):795-801.

12. Liew G, Wang JJ, Mitchell P. Migraine and coronary heart disease mortality: a prospective cohort study. Cephalalgia. 2007;27(4):368-371.

13. Scher AI, Gudmundsson LS, Sigurdsson S, Ghambaryan A, Aspelund T, Eiriksdottir G, van Buchem MA, et al. Migraine headache in middle age and late-life brain infarcts. JAMA. 2009;301(24):2563-2570.

14. Tietjen GE. Migraine as a systemic disorder. Neurology. 2007;68(19):1555-1556.

15. Vargas BB, Dodick DW, Wingerchuk DM, Demaerschalk BM. Migraine with and without aura and risk for cardiovascular disease. Curr Atheroscler Rep. 2008;10(5):427-433.

16. Kurth T, Schurks M, Logroscino G, Buring JE. Migraine frequency and risk of cardiovascular disease in women. Neurology. 2009;73(8):581-588.

17. Scher AI, Terwindt GM, Picavet HS, Verschuren WM, Ferrari MD, Launer LJ. Cardiovascular risk factors and migraine: the GEM population-based study. Neurology. 2005;64(4):614-620.

18. Monastero R, Pipia C, Cefalu AB, Liveri ET, Rosano R, Camarda R, Camarda C. Association between plasma lipid levels and migraine in subjects aged $>$ or $=50$ years: preliminary data from the Zabut Aging Project. Neurol Sci. 2008;29 Suppl 1:S179-181.

19. Gruber HJ, Bernecker C, Pailer S, Lechner A, Horejsi R, Moller R, Fazekas F, et al. Lipid profile in normal weight migraineurs - evidence for cardiovascular risk. Eur J Neurol. 2010;17(3):419-425.

20. Vanmolkot FH, de Hoon JN. Increased C-reactive protein in young adult patients with migraine. Cephalalgia. 2007;27(7):843-846.

21. The International Classification of Headache Disorders: 2nd edition. Cephalalgia. 2004;24 Suppl 1:9-160.

22. Bayliss MS, Dewey JE, Dunlap I, Batenhorst AS, Cady R, Diamond ML, Sheftell F. A study of the feasibility of Internet administration of a computerized health 
survey: the headache impact test (HIT). Qual Life Res. 2003;12(8):953-961.

23. Cook NR, Bensenor IM, Lotufo PA, Lee IM, Skerrett PJ,
Chown MJ, Ajani UA, et al. Migraine and coronary heart disease in women and men. Headache. 2002;42(8):715727. 